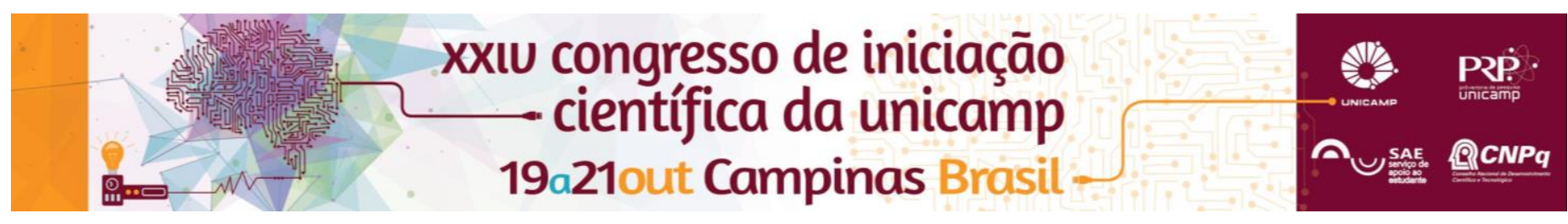

\title{
Investigação de Deleções Talassêmicas Raras por Multiplex Ligation-dependent Probe Amplification (MLPA)
}

\author{
Natália O. Mota, Roberta D. Ferreira*, Gisele A. Pedroso, Elza M. Kimura, Ana M. Soler, Julio Luz, Maria F. Sonati
}

\section{Resumo}

Talassemias são hemoglobinopatias hereditárias com distribuição mundial. Sua caracterização molecular permite a elucidação diagnóstica, o aconselhamento e o tratamento mais adequado dos portadores. O MLPA tem sido empregado para identificação e caracterização de deleções gênicas relacionadas a essa hemoglobinopatia. Neste trabalho foram caracterizadas oito deleções $\alpha$-talassêmicas novas ou raras e uma deleção no agrupamento dos genes da globina $\beta$ relacionada a uma forma muito rara de talassemia, a $\varepsilon \gamma \delta \beta$-talassemia.

\section{Palavras-chave:}

Talassemia $\alpha, \varepsilon \gamma \delta \beta$-Talassemia, MLPA.

\section{Introdução / Objetivo}

Talassemias são hemoglobinopatias hereditárias caracterizadas pela síntese reduzida/ausente de cadeias globínicas. $\mathrm{Na}$ talassemia $\alpha$, a deficiência de globinas a comumente resulta de deleções nos genes $\alpha_{2}$ e/ou $\alpha_{1}$ (16p13.3), enquanto na talassemia $\beta$, a deficiência de cadeias $\beta$ é geralmente causada por mutações de ponto nos genes $\beta$ (11p15.5). O objetivo deste trabalho foi caracterizar as bases moleculares das talassemias em nove indivíduos não relacionados $(P)$, oito brasileiros e um uruguaio, sendo oito casos sugestivos de talassemia $\alpha$ e um de talassemia $\beta$.

\section{Casuística}

Tabela 1. Dados Hematológicos dos Pacientes.

\begin{tabular}{|c|c|c|c|c|c|c|c|c|c|}
\hline Casos & P1 & P2 & $\mathrm{P}_{3}$ & P4 & P5 & P6 & P7 & P8 & P9 \\
\hline Idade/Gênero & $3 \mathrm{~m} / \mathrm{F}$ & $17 / \mathrm{M}$ & $35 / \mathrm{F}$ & $58 / \mathrm{F}$ & $-/ F$ & $2 \mathrm{~m} / \mathrm{F}$ & $37 / M$ & $2 / \mathrm{M}$ & $1 \mathrm{~d} / \mathrm{F}$ \\
\hline 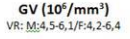 & 4,55 & 5,43 & 5,50 & 5,50 & 5,00 & 4,64 & 55,5 & 5,45 & 4,25 \\
\hline 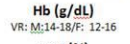 & 7,75 & 8,8 & 11,2 & 12,5 & 8,3 & 8,1 & 9,2 & 10,6 & 8,4 \\
\hline 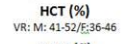 & - & 30,4 & 35,9 & 41,4 & 29,7 & 28,9 & 16,6 & - & 30,4 \\
\hline $\begin{array}{c}\text { VMM (ffl) } \\
\text { VR:M:81.99/: } 80.96\end{array}$ & 17,0 & 56 & 65,3 & 70,4 & 59,4 & 62,3 & 61,6 & 58,5 & 71,1 \\
\hline $\begin{array}{l}\text { HCM (pg) } \\
\text { VR: } 27.32\end{array}$ & 54,1 & 16,2 & 20,4 & 22,4 & 16,6 & 17,5 & 34,2 & 19,40 & 19,8 \\
\hline $\begin{array}{l}\text { RDW (\%) } \\
\text { VR: } 10.15\end{array}$ & - & 24,4 & 15,1 & 16,4 & - & 26,0 & 25,5 & 17,2 & 29,0 \\
\hline Perfil Hb & $\begin{array}{l}A_{2} A_{A}, H, H^{\prime} \\
\text { Bart's }\end{array}$ & $A_{2} A_{1}, \mathrm{H}$ & $A_{2}, A$ & $A_{2}, A$ & $\begin{array}{l}A_{2}, A_{1} H_{1}, \\
\text { Bart's }\end{array}$ & $\begin{array}{l}A_{2} A_{A} \mathrm{H}^{\prime} \text {, } \\
\text { Bart's }\end{array}$ & $A_{2} A_{1}, H$ & $A_{2}, A$ & $\mathrm{C}(21,9 \%)_{\mu} \mathrm{F}$ \\
\hline 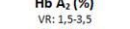 & 0,78 & 1,6 & 2,6 & 2,5 & 0,8 & 1,0 & 1,5 & 2,9 & - \\
\hline $\begin{array}{l}\mathrm{HbF} \text { F }(\%) \\
\mathrm{VR}:<2\end{array}$ & 23,7 & 0,1 & 0,6 & 0,4 & 1,7 & 22,6 & 0,5 & - & 77,8 \\
\hline $\mathrm{Hb} H(\%)$ & 10,0 & 3,0 & - & - & 7,6 & $\begin{array}{c}18,9 \\
\text { (Bart's + H) }\end{array}$ & 4,0 & - & - \\
\hline
\end{tabular}

\section{Materiais e Métodos}

A investigação e caracterização molecular foram realizadas através das técnicas de:

- Multiplex-gap-PCR: Sete deleções a-talassêmicas

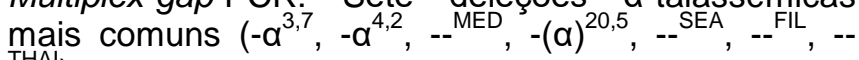
THAl)

- Análise com enzimas de restrição: Mutações não delecionais ( $\left.\alpha^{\text {Hph }} \alpha, \alpha^{\text {Ncol }} \alpha, \alpha \alpha^{\text {Ncol }}, \alpha^{\text {TSaudi }} \alpha\right)$

- Sequenciamento dos genes $\alpha$ e $\beta$

- Multiplex Ligation-dependent Probe Amplification (MLPA), empregando os kits Salsa MLPA P102 C1 HBB e Salsa MLPA P140 C1 HBA (MRC Holland, Amsterdã, Holanda) para 0 cluster $\beta$ e $\alpha$ respectivamente.

\section{Resultados}

Nos casos de talassemia $\alpha$ :

- P1, P2, P5, P6 e P7: Doença da Hb H - associação da deleção $-\alpha^{3,7}$ com deleção $\alpha^{0}$ (genótipo $-\alpha^{3,7} /--$ );

- P1 a P8: deleções $a^{0}$ variando de 15-225 kb de DNA;
No caso de talassemia $\beta$ :

- P9: Heterozigose de deleção $\beta^{0}$ que remove entre 172 e $283 \mathrm{~kb}$ de DNA, resultando em $\varepsilon \gamma \delta \beta$-talassemia.

Entre as nove deleções, sete são potencialmente novas, sendo exceções as deleções - $(\alpha)^{5,2}$ e --MEDII, já descritas, porém pela primeira vez detectadas na América Latina.

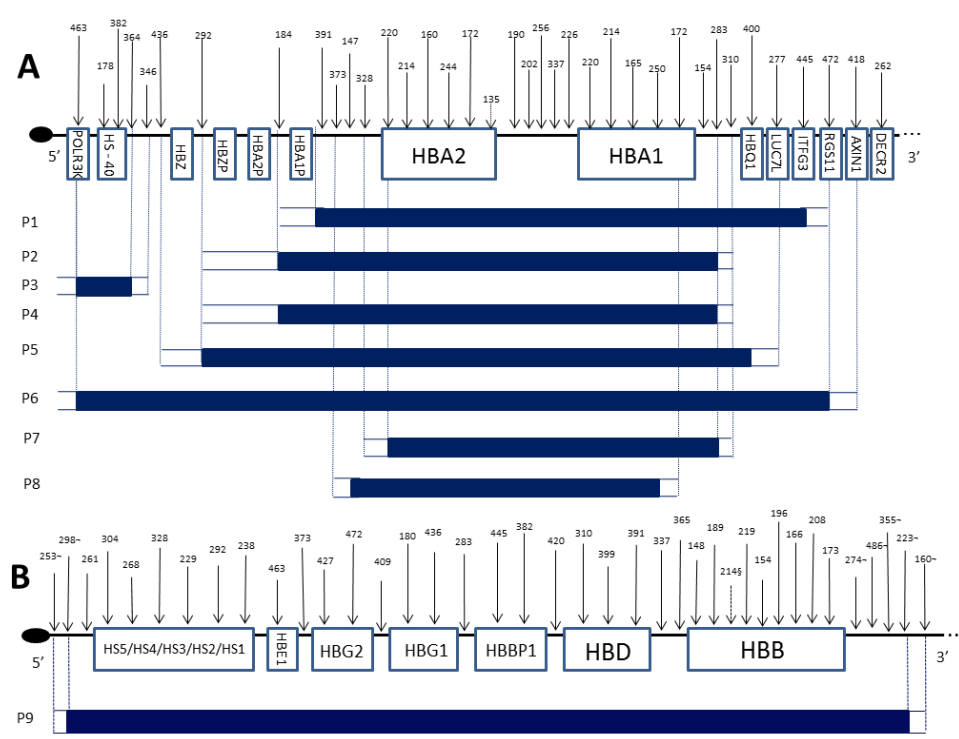

Figura 1. Representação esquemática de 16p13.3 (A) e 11p15.5 (B). Forma oval: Região telomérica; Flechas: Localizações das sondas; Caixas: Disposição dos genes; Barras azuis: Fragmento deletado; Linhas pontilhadas: Primeira e a última sonda deletada (Adaptado de MRCHolland, 2014).

\section{Discussão e Conclusões}

Estes resultados enfatizam a diversidade de alterações moleculares que afetam os genes de globinas e a relevância de sua caracterização, uma vez que as alterações hematológicas apresentadas pelos portadores podem levar a interpretações equivocadas $e$, eventualmente, a abordagens terapêuticas inadequadas. Destaca-se ainda a importância do método de MLPA na caracterização das talassemias delecionais.

\section{Financiamento}

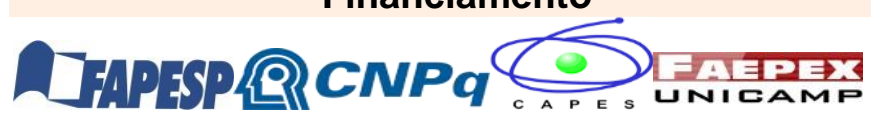

